\title{
Insights to indications and harm of proton pump inhibitors usage in patients with liver cirrhosis
}

\begin{abstract}
P.P.I therapy is often used in patients with cirrhosis, sometimes, in the absence of a specific indication (e.g.: acid related diseases), there are conflicting reports for their use in cirrhotic patients. The dosage of most PPIs should be reduced in cirrhotic as they are metabolized by the liver and associated with adverse effects of prolonged use.
\end{abstract}

Keywords: proton pump inhibitors, liver cirrhosis, peptic ulcer, H. pylori, esophageal band ligation
Volume 7 Issue 5 - 2015

Fady Maher Wadea

Department of Internal Medicine, Zagazig University, Egypt

Correspondence: Fady Maher Wadea,Assistant professor
of Internal Medicine department, Gastroenterology and
Hepatology division, faculty of Medicine, Zagazig University,
Egypt, Email fadymaher4I @yahoo.com

Received: May 22, 2017 | Published: September 07, 2017

\begin{abstract}
Abbreviations: PPI, proton pump inhibitors; EVS, esophageal variceal sclerotherapy; EVL, esophageal variceal ligation; HE, hepatic encephalopathy; SBP, spontaneous bacterial peritonitis; CDI, clostridium difficile infection; PHG, portal hypertensive gastropathy; GERD, gastroesophageal reflux disease; LES, lower esophageal sphincter
\end{abstract}

\section{Introduction}

A significant proportion of cirrhotic patients are prescribed for PPIs. ${ }^{1}$ The indication for PPI prescription in many of these patients is weak or unclear, 2,3 in their study, Bajaj et al. Found that half of their patient population did not have either an established or appropriate indication for PPI therapy usage. ${ }^{4}$ Proton pump inhibitors facilitate bacterial overgrowth in G.I.T and may promote serious infections leading to liver function deterioration and increasing mortality so, a careful use of PPI in cirrhotic should be announced, especially when they are used away from hard indications. We aimed to review strict indications for their use in this group of patients.

\section{Discussion}

\section{Esophageal varices}

EVS and EVL procedures produce local complications such as esophageal ulcerations, strictures, and perforations. ${ }^{5}$ Uncontrolled non-randomized studies showed that PPI may have a role in the prevention and healing of post-EVS ulcerations ${ }^{6}$ and in prevention of gastro esophageal reflux produced by esophageal wall motor dysfunction. ${ }^{7}$ Pantoprazole has been shown to reduce the size of ulcers in patients undergoing elective band ligation and PPI treatment is advisable in patients undergoing this procedure. A short course for 10 days post-EVL may be reasonable if we concern for ulcer healing. However, high-dose infusion (e.g., pantoprazole $8 \mathrm{mg} / \mathrm{h}$ ) and prolonged use in the absence of endoscopic procedures is not supported by the literature and should be discouraged until evidence of benefit becomes available. ${ }^{8}$

\section{GERD}

Functional studies showed decreased LES function with low amplitude of acid clearance and primary esophageal peristalsis in cirrhotic patients with large varices. ${ }^{9}$ These phenomena could be due to a mechanical effect of the varices. Cirrhotic patients without
EV have also esophageal motor disorders and mixed acid and bile reflux as the main pattern, whereas the cirrhosis itself is an important causative factor. It is unclear whether this might contribute to bleeding from varices. ${ }^{8}$ Data on management of GERD in cirrhosis are few, however, the indications of use for PPIs may remain exactly the same in patient with cirrhosis of the liver as general population for the treatment of erosive esophagitis, or in general the pathology secondary to gastroesophageal reflux of acid. ${ }^{10}$

\section{Peptic ulcer and $\mathbf{H}$. pylori infection}

Prevalence of duodenal and gastric ulcers in patients with liver cirrhosis increases as the disease progress ${ }^{11}$ and this prevalence becomes higher in decompensated cirrhosis than in compensated cirrhosis. ${ }^{12}$ Currently, PPIs are the mainstay treatment option of peptic ulcers in the general population. ${ }^{13}$ Helicobacter pylori infection contributes to the development of hyperammonemia ${ }^{14}$ and subsequent episodes of hepatic encephalopathy in cirrhosis.$^{15}$. H. Pylori eradication has been improved by the use of PPIs-based triple therapy. ${ }^{16}$ Blood ammonia concentration was significantly reduced after PPIs-based triple treatment in cirrhotic patients. ${ }^{14,15}$ Therefore, it might be of value that PPIs can reduce the risk of hepatic encephalopathy development in cirrhotic patients infected with Helicobacter pylori.$^{17}$

A meta-analysis done by Vergara et al. ${ }^{18}$ showed that Helicobacter pylori infection was a risk factor for developing peptic ulcers in cirrhotic patients. ${ }^{18}$ Similar observations were found in Calvet et al. ${ }^{19}$ study. Thus, Helicobacter pylori eradication with PPIs treatment may be necessary. If $H$. Pylori infection were an etiopathological factor implicated in digestive bleeding in cirrhosis, eradication of infection would decrease the risk of ulcer recurrence, however; other studies show conflicting results as regards no decreased risk of ulcer recurrence. $^{17}$

\section{Portal hypertensive gastropathy}

Proton pump inhibitors, sucralfate, and histamine-2 receptor antagonists are not very effective at reducing bleeding from PHG because most patients with PHG already have hypochlorhydria. ${ }^{20}$ However, proton pump inhibitors may indirectly stop bleeding from the stomach by raising intraluminal gastric $\mathrm{pH}$ and thereby stabilizing blood clots..$^{21,22}$ Additionally, patients whose bleeding were refractory to vasopressin benefited from omeprazole co-administration and vice versa. 


\section{Harms of P.P.I usage in cirrhotic patients}

Harms unique to the liver: SBP and HE: ${ }^{8}$ PPI decrease gastric acid production and raise the $\mathrm{pH}$ of the stomach, elimination of the gastric acid barrier facilitates intestinal bacterial overgrowth. This increases the risk of translocation of gut bacteria to the mesenteric lymph nodes and from there to the blood and lymph with the end result is systemic inflammation, which is an important second hit-after the first hit, hyperammonemia-in HE development. ${ }^{23}$

PPIs promote the small intestinal bacterial overgrowth and altered intestinal motility, which might be the pathogenesis of SBP. Some evidence had shown that PPIs treatment was a predisposing factor for SBP in patients with cirrhosis which might be related to the dosage and duration of PPIs. ${ }^{24}$

Acute hepatitis: In patients with hepatic dysfunction, the pharmacokinetics of PPIs changes. ${ }^{25}$ Case reports of acute hepatitis in even subjects without previous liver disease have been reported for omeprazole, lansoprazole and recently pantoprazole. It is difficult to state whether the hepatotoxicity related to these drugs is a class effect due to the basic benzimidazole structure shared by these drugs. However, cross-hepatotoxicity between different PPIs has not been described. ${ }^{26}$

\section{Harms occur in cirrhotic patients and general populations}

Osteoporosis and bone fractures due to hypocalcemia. Infectious enteric complications, such as a twofold increased risk of Clostridium (CDI) difficile infection ${ }^{27}$ and a higher frequency of community.$^{28}$ and ventilator acquired pneumonia. ${ }^{29}$ PPIs may contribute to deficiencies of B12, iron and magnesium, acute interstitial nephritis and rebound acid hypersecretion with drug cessation. ${ }^{30}$

\section{Dosing of P.P.I in liver diseases}

In the case of liver impairment, the Area Under the Curve for PPIs increases and their half-life becomes $4 \mathrm{~h}$ to $8 \mathrm{~h}$ greater, ${ }^{31}$ the risk of their accumulation increase. This effect was also seen with rabeprazole ${ }^{32}$ however; a dose reduction seems to be unnecessary with a $20 \mathrm{mg}$, once daily dose in patients with mild to moderate liver cirrhosis. When using other PPIs or rabeprazole at $40 \mathrm{mg} / \mathrm{d}$, dose reduction is advisable (Figure 1).

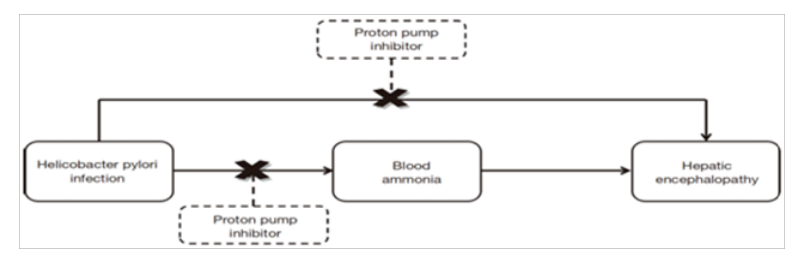

Figure I Possible relationship between proton pump inhibitor and decreased risk of hepatic encephalopathy in $\mathrm{H}$. pylori infected patients. ${ }^{17}$

YP2C19 is the main metabolic pathway for P.P.I, the affinity for different PPIs is different and rabeprazole is metabolized mainly by a non enzymatic pathway. There are two CYP2C19 phenotypes: extensive and poor metabolisers. Poor metabolisers have higher plasma levels of PPI, which could lead to higher efficacy, but also to potential adverse events. The effects of these genotypes varies according to the specific PPI used and in general is greater when using omeprazole decreasing progressively to lansoprazole, esomeprazole, pantoprazole and finally rabeprazole. ${ }^{33}$

\section{Conclusion}

The widespread prescription of PPIs in cirrhotic patients needs to be revised. PPIs can be used to effectively control the complications following endoscopic treatment for esophageal varices and reduce the risk of ulcers or hepatic encephalopathy related to the Helicobacter pylori infection or stabilization of blood clot in bleeding ulcer or PHG which are the potential indications. On the other hand, the use of PPIs may increase the incidence of serious adverse events as bone fracture, CDI, pneumonia, SBP and HE with long term use.

\section{Aknowledgments}

None.

\section{Conflicts of interest}

The authors declare there is no conflict of interest.

\section{Funding}

None.

\section{References}

1. Dultz G, Piiper A, Zeuzem S, et al. Proton pump inhibitor treatment is associated with the severity of liver disease and increased mortality in patients with cirrhosis. Aliment Pharmacol Ther. 2015;41(5):459-466.

2. Merli M, Lucidi C, Di Gregorio V, et al. The chronic use of beta-blockers and proton pump inhibitors may affect the rate of bacterial infections in cirrhosis. Liver Int. 2015;35(2):362-329.

3. Mandorfer M, Bota S, Schwabl P, et al. Proton pump inhibitor intake neither predisposes to spontaneous bacterial peritonitis or other infections nor increases mortality in patients with cirrhosis and ascites. PLOS ONE. 2014;9(11):e110503.

4. Bajaj JS, Zadvornova Y, Heuman DM, et al. Association of proton pump inhibitor therapy with spontaneous bacterial peritonitis in cirrhotic patients with ascites. Am J Gastroenterol. 2009;104(5):1130-1134.

5. Krige JE, Bornman PC, Shaw JM, et al. Complications of endoscopic variceal therapy. S Afr J Surg. 2005;43(4):177-188,190-194.

6. Jaspersen D, Korner T, Schorr W, et al. Omeprazole in the management of sclerotherapy-induced esophageal ulcers resistant to $\mathrm{H} 2$ blocker treatment. J Gastroenterol. 1995;30(1):128-130.

7. Grande L, Planas R, Lacima G, et al. Sequential esophageal motility studies after endoscopic injection sclerotherapy:a prospective investigation. Am J Gastroenterol. 1991;86(1):36-40.

8. Lodato F, Azzaroli F, Di Girolamo M, et al. Proton pump inhibitors in cirrhosis:tradition or evidence based practice? World J Gastroenterol. 2008;14(19):2980-2985.

9. Flores PP, Lemme EM, Coelho HS. Esophageal motor disorders in cirrhotic patients with esophageal varices non-submitted to endoscopic treatment. Arq Gastroenterol. 2005;42(4):213-220.

10. Picardi A. Proton Pump Inhibitor Prescription in Patients with Liver Cirrhosis:Indications in Theory and the Real World. J Liver Res Disord Ther. 2015;1(1):00046.

11. Wu CS, Lin CY, Liaw YF. Helicobacter pylori in cirrhotic patients with peptic ulcer disease:a prospective, case controlled study. Gastrointest Endosc. 1995;42:424-427.

12. Wu CS, Lin CY, Liaw YF. Helicobacter pylori in cirrhotic patients with peptic ulcer disease:a prospective, case controlled study. Gastrointest Endosc. 1995;42(5):424-427. 
13. Kim HU. Diagnostic and Treatment Approaches for Refractory Peptic Ulcers. Clin Endosc. 2015;48(4):285-290.

14. Chen SJ, Wang LJ, Zhu Q, et al. Effect of $H$ pylori infection and its eradication on hyperammo-nemia and hepatic encephalopathy in cirrhotic patients. World J Gastroenterol. 2008;14(12):1914-1918.

15. Agrawal A, Gupta A, Chandra M, et al. Role of Helicobacter pylori infection in the pathogenesis of minimal hepatic encephalopathy and effect of its eradication. Indian J Gastroenterol. 2011;30(1):29-32.

16. Jung SW, Lee SW, Hyun JJ, et al. Efficacy of Helicobacter pylori eradication therapy in chronic liver disease. Dig Liver Dis. 2009;41(2):134-140.

17. Jia Zhu, Haonan Yu, Andrea Mancuso, et al. Proton pump inhibitors in liver cirrhosis:a review of benefits and harms. AME Medical Journal. 2017;36:1-9.

18. Vergara M, Calvet X, Roqué M. Helicobacter pylori is a risk factor for peptic ulcer disease in cirrhotic patients. A meta-analysis. Eur $J$ Gastroenterol Hepatol. 2002;14(7):717-722.

19. Calvet X, Navarro M, Gil M, et al. Epidemiology of peptic ulcer disease in cirrhotic patients:role of Helicobacter pylori infection. Am J Gastroenterol. 1998;93(1):2501-2507.

20. Zhou Y, Qiao L, Wu J, et al. Comparison of the efficacy of octreotide, vasopressin, and omeprazole in the control of acute bleeding in patients with portal hypertensive gastropathy:a controlled study. J Gastroenterol Hepatol. 2002;17(9):973-979.

21. Yen $\mathrm{HH}$, Yang $\mathrm{CW}, \mathrm{Su} \mathrm{WW}$, et al. Oral versus intravenous proton pump inhibitors in preventing re-bleeding for patients with peptic ulcer bleeding after successful endoscopic therapy. BMC Gastroenterol. 2012;12:66.

22. Pang SH, Graham DY. A clinical guide to using intravenous protonpump inhibitors in reflux and peptic ulcers. Therap Adv Gastroenterol. 2010;3(1):11-22.

23. Sturgeon JP, Shawcross DL. Recent insights into the pathogenesis of hepatic encephalopathy and treatments. Expert Rev Gastroenterol Hepatol. 2014;8(1):83-100.
24. Xu HB, Wang HD, Li CH, et al. Proton pump inhibitor use and risk of spontaneous bacterial peritonitis in cirrhotic patients:a systematic review and meta-analysis. Genet Mol Res. 2015;14(3):7490-7501.

25. Delhotal-Lands B, Flouvat B, Duchier J, et al. Pharmacokinetics of lansoprazole in patients with renal or liver disease of varying severity. Eur J Clin Pharmacol. 1993;45(4):367-371.

26. Darabi K. Proton-pump-inhibitor-induced hepatitis. South Med J. 2005;98(8):844-845.

27. Jump RL, Pultz MJ, Donskey CJ. Vegetative Clostridium difficile survives in room air on moist surfaces and in gastric contents with reduced acidity:a potential mechanism to explain the association between proton pump inhibitors and C. difficile-associated diarrhea? Antimicrob Agents Chemother. 2007;51(8):2883-2887.

28. Laheij RJ, Sturkenboom MC, Hassing RJ, et al. Risk of communityacquired pneumonia and use of gastric acid-suppressive drugs. JAMA. 2004;292(16):1955-1960.

29. Prod'hom G, Leuenberger P, Koerfer J, et al. Nosocomial pneumonia in mechanically ventilated patients receiving antacid, ranitidine, or sucralfate as prophylaxis for stress ulcer a randomized controlled trial. Ann Int Med. 1994;120(8):653-662.

30. Abraham NS. Proton pump inhibitors:potential adverse effects. Curr Opin Gastroenterol. 2012;28(6):615-620.

31. Thjodleifsson B. Treatment of acid-related diseases in the elderly with emphasis on the use of proton pump inhibitors. Drugs Aging. 2002;19(12):911-927.

32. Hoyumpa AM, Trevino-Alanis H, Grimes I, et al. Rabeprazole:pharmacokinetics in patients with stable, compensated cirrhosis. Clin Ther. 1999;21(4):691-701.

33. Ishizaki T, Horai Y. Review article: cytochrome $\mathrm{P} 450$ and the metabolism of proton pump inhibitors-emphasis on rabeprazole. Aliment Pharmacol Ther. 1999;13(3):27-36. 